\title{
Review on technologies used to design RF diplexers
}

\begin{abstract}
In this review paper, we present the recent progress in the design of RF diplexers. It is known that diplexers play an important role in many modern telecommunication systems. In this context, several types of diplexers have been proposed in literature. This review is particularly interested in working principle and diplexers role in wireless communication systems. It also discusses the main features of a diplexer and a general comparison between the various technologies used to design the diplexer circuits.
\end{abstract}

Volume 4 Issue I - 2018

\author{
Abdessamed Chinig \\ University Hassan Ist, Morocco \\ Correspondence: Abdessamed Chinig, University Hassan Ist, \\ Ben Street 13 Oued Zem, Morocco, Tel +2I26I5236364, \\ Email abdo.chinig@gmail.com
}

Received: February 01, 2018 | Published: February 16, 2018

\section{Introduction}

In recent years, the digital world has seen the advent of new mobile applications with bandwidth- intensive activities. In fact, this phenomenal evolution of systems and applications dedicated to wireless communication has been a direct consequence of scientific and technical advances in this field. In this perspective, improving the use of these applications requires a great need for bandwidth. In order to optimize the use of bandwidth, multiservice and multistandards wireless communication systems represent an attractive solution. In fact, realizing a multiservice system requires the use of the duplexing function, which allows a transceiver to carry out a bidirectional communication. For this purpose, two duplexing procedures are commonly used: TDD (Time-Division Duplexing) and FDD (frequency-Division Duplexing). Transceivers that use FDD duplexing require simultaneous operation of the transmitter and receiver that share the same antenna. For that, two separate bandwidths are used for transmission and reception. Therefore, it is necessary to use a diplexer consisting of two very selective filters one centered on the transmission band and the other on the receive band to separate the transmission and reception signals. Due to the finite isolation of the diplexer, strong leakage of the transmission signal desensitizes the receiving path. Thus, the design of this type of circuit is not simple and it is necessary to achieve a diplexer with high isolation and low insertion loss to ensure proper functioning of the entire system.

Unlike frequency duplexing, time duplexing allows multiple signals to be transmitted over a single channel. The transmitter and receiver operate almost simultaneously at different points in time. Considering all the design constraints already mentioned, several efforts have been made by researchers and designers to develop new solutions for the design of diplexers with better performances in terms of selectivity, loss, size and cost.

\section{Diplexer Circuits and their Applications}

Diplexers are key components in several communication systems, including radio transmission, mobile telephony, satellite communication systems and broadband wireless communications. Diplexers were widely studied in the 1960 s by Matthaei et al. ${ }^{1}$ \& Wenzel. ${ }^{2}$ They are very selective components used to combine or separate signals with different center frequencies. Generally, the diplexers consists of two filters, known as channel filters, and a common junction used to combine the two filters in order to form the multiport network. These diplexers allow to an antenna to be shared simultaneously by a transmitter and a receiver, which operate at separate frequency bands with a minimum interaction between the transmitted and received signals. As a result, a reduction in terms of size and weight is possible thanks to the use of a single antenna. ${ }^{3}$ The diplexer ports are the transmit port the receive port and the antenna port. Each diplexer is a combination of two filters. One connected to the transmitter, the other connected to the receiver and the third port represents the point of connection between the two filters and the antenna. The basic principle of a diplexer is to route the signal from the antenna to the receive channel and to transmit the signal from the transmission channel to the antenna with an isolation between the transmission and the reception channels as shown in the Figure 1. Several approaches are possible to design RF diplexers, however three of them are frequently used: ${ }^{4}$

i. The use of two band-pass filters with different center frequencies.

ii. The use of a band-pass filter for one channel and a band-stop filter rejecting the same frequency band for the other channel.

iii. The use of two band-stop filters with different center frequencies.

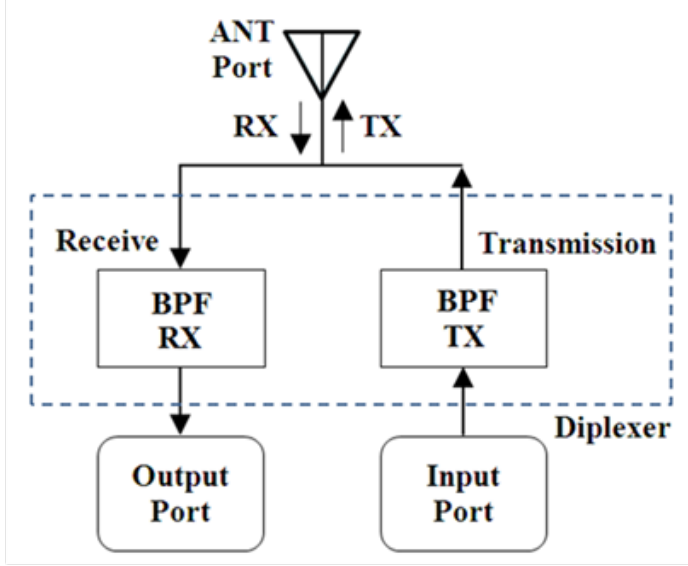

Figure I Block diagram of a diplexer.

\section{Comparison between the different technologies used to design RF diplexers}

The designs of an RF filter or a diplexer require the choice of a technology. This technological choice depends on several factors such as frequency response requirements, circuit complexity, size, 
cost, handling power, insertion losses, and isolation. Table 1 gives the main characteristics of the technologies used to design diplexer circuits. In fact, there is two main technologies used to fabricate RF diplexers: waveguide and planar. Despite its interesting electrical characteristics in terms of high quality factors, selectivity, and low insertion losses, waveguides diplexers suffer from many problems in terms of weight, cost and reproducibility. Planar diplexers are much known for their small size, low cost production, they can be fully integrated with surrounding electronics circuits and it is easy to reproduce them. However, they suffer from low quality factors, poor selectivity and significant insertion losses. For that, the current trend tends to miniaturize RF filters and diplexers by defining new structures and topologies that are more complex. Therefore, the main objective of planar technologies is to improve the propagation characteristics of these structures while reducing their size. Besides, to overcome such problems many technologies have been proposed in literature to enhance the electrical performances such as (HTS, SAW/ BAW, SIW...).

Table I Comparison between the different technologies used to design RF diplexers.

\begin{tabular}{|c|c|c|c|c|c|c|c|}
\hline & $\begin{array}{l}\text { Waveguides } \\
\text { diplexers }\end{array}$ & $\begin{array}{l}\text { Dielectric } \\
\text { resonators } \\
\text { diplexers }^{7,8}\end{array}$ & $\begin{array}{l}\text { Planar } \\
\text { diplexers } 9,10\end{array}$ & $\begin{array}{l}\text { Quasi-planar } \\
\text { diplexers }^{11,12}\end{array}$ & $\begin{array}{l}\text { SAW/BAW } \\
\text { diplexers }^{13,14}\end{array}$ & $\begin{array}{l}\text { SIW } \\
\text { diplexers }^{15,16}\end{array}$ & HTS \\
\hline Frequency $(\mathrm{GHz})$ & $5-100 \mathrm{GHz}$ & $0.5-100 \mathrm{GHz}$ & $0.5-100 \mathrm{GHz}$ & $5-100 \mathrm{GHz}$ & $<10 \mathrm{GHz}$ & $0.5-100 \mathrm{GHz}$ & $0.5-100 \mathrm{GHz}$ \\
\hline Quality factor & Very High & Very High & Low & High & Moderate & High & Low \\
\hline Integrability & Difficult & Difficult & Excellent & Moderate & Moderate & Moderate & Excellent \\
\hline Size & Large & Large & Small & Large & Small & Moderate & Small \\
\hline Power Handling & High & High & Low & High & Moderate & Low & Low \\
\hline Fabrication Cost & High & High & Low & High & Low & Moderate & Low \\
\hline EM Simulation & $\begin{array}{l}\text { Electromagnetic } \\
\text { Simulations 3D }\end{array}$ & $\begin{array}{l}\text { Electromagnetic } \\
\text { Simulations 3D }\end{array}$ & $\begin{array}{l}\text { Models, } \\
\text { Electromagnetic } \\
\text { Simulations 2D } \\
\text { and 3D }\end{array}$ & $\begin{array}{l}\text { Electromagnetic } \\
\text { Simulations 3D }\end{array}$ & $\begin{array}{l}\text { Electromagnetic+ } \\
\text { acoustic } \\
\text { Simulations }\end{array}$ & $\begin{array}{l}\text { Electromagnetic } \\
\text { Simulations 3D }\end{array}$ & $\begin{array}{l}\text { Models, } \\
\text { Electromagnetic } \\
\text { Simulations 2D } \\
\text { and 3D }\end{array}$ \\
\hline Production Time & $\begin{array}{l}\text { Important } \\
\text { (Tuning) }\end{array}$ & $\begin{array}{l}\text { Important } \\
\text { (Tuning) }\end{array}$ & Medium & $\begin{array}{l}\text { Important } \\
\text { (Tuning) }\end{array}$ & Low & $\begin{array}{l}\text { Important } \\
\text { (Tuning) }\end{array}$ & Low \\
\hline Reproducibility & $\begin{array}{l}\text { Difficult } \\
\text { (Manual Tuning) }\end{array}$ & $\begin{array}{l}\text { Difficult } \\
\text { (Manual Tuning) }\end{array}$ & Excellent & $\begin{array}{l}\text { Difficult } \\
\text { (Tuning) }\end{array}$ & Excellent & $\begin{array}{l}\text { Difficult } \\
\text { (Tuning) }\end{array}$ & Excellent \\
\hline
\end{tabular}

\section{Conclusion}

The realization of a telecommunications system with good electrical performance, compact size and low cost is still a challenge for designers and researchers. ${ }^{17}$ In this context, we have shown in this review that the use of diplexers in wireless communication systems represents an attractive solution for reducing the systems size, consumption and manufacturing cost. Therefore, it is necessary to provide new solutions to design diplexers in order to satisfy all the constraints imposed by the clients. All these criteria can be achieved by taking advantage of the possibilities offered by the advances in the computer science field and the electromagnetic simulation tools.

\section{Acknowledgements}

None.

\section{Conflict of interest}

The author declares no conflict of interest.

\section{References}

1. Matthaei GL, Cristal EG. Multiplexer channel-separating units using interdigital and parallel-coupled filters. Microwave theory and techniques. IEEE Transactions on Microwave Theory and Techniques. $1965 ; 13(3): 328-334$

2. Wenzel RJ. Printed-circuit complementary filters for narrow bandwidth multiplexers. Microwave theory and techniques. IEEE Transactions on Microwave Theory and Techniques. 1968;16(3):147-157.
3. Rocha CC, Soares AJM, Abdalla H. Microwave multiplexers using complementary filters. Applied Microwave and Wireless. 1998;10:28-37.

4. Gouget P. Etude de circuits hyperfréquences utilisant la jonction inhomogène ligne à fente, ligne micro-ruban : application à l'intégration de filtres et de diplexeurs (Thèse de Doctorat, Bordeaux 1, France) ; 2004.

5. Vanin FM, Schmitt D, Levy R. Dimensional synthesis for wide-band waveguide filters and diplexers. Microwave theory and techniques. IEEE Transactions on Microwave Theory and Techniques. 2004;52(11):24882495 .

6. Mansour RR. RF filters and diplexers for wireless system applications: State of the art and trends. In Radio and Wireless Conference, RAWCON'03. Proceedings, USA: IEEE; 2003.

7. Mohottige N, Budimir D, Golubicić Z. Compact dielectric-filled waveguide filters and diplexers. In Antennas and Propagation Society International Symposium (APSURSI), USA: IEEE; 2012.

8. Hong S, Chang K. Stub-tuned Microstrip Band pass Filters for Millimeterwave diplexer design. In Microwave and Wireless Components Letters. 2005;15(9):582-584.

9. Chen CF, Huang TY, Chou CP, et al. Microstrip diplexers design with common resonator sections for compact size, but high isolation. IEEE Transactions on Microwave Theory and Techniques. 2006;54(5):19451952.

10. Yun SH, Uhm MS, Yom IB. Design of the multipaction free high power Ka-band diplexer with an E-plane T-junction. In Communications, 2005 Asia-Pacific Conference on Communications; Australia: IEEE; 20005. 
11. Zhang D, Zhao Y, Liu W, et al. A fast synthesis approach for diplexer with E-plane T-junction design. In Information Science and Engineering (ISISE), 2010 International symposium on information science and engineering, China: IEEE; 2010.

12. Shiba T, Hikin O, Kondo S, et al. SAW duplexer design for WCDMA system. In Ultrasonics Symposium (IUS), IEEE International; Italy: IEEE; 2009

13. Yun-Kwon P, Kuang-Woo N, Seok-Chool Y, et al. Fabrication of monolithic 1-Chip FBAR duplexer for W-CDMA handsets. In micro electro mechanical systems, IEEE $20^{\text {th }}$ International conference on micro electro mechanical systems (MEMS), Japan: IEEE; 2007.

14. Tang HJ, Hong W, Chen JX, et al. Development of millimeter-wave planar diplexers based on complementary characters of dual-mode substrate integrated waveguide filters with circular and elliptic cavities. IEEE Transactions on Microwave Theory and Techniques. 2007;55(4):776782
15. Garcia-Lamperez A, Salazar-Palma M, Yeung SH. Compact diplexer with dual-mode SIW resonators. In European Microwave Conference (EuMC), Italy: IEEE; 2014.

16. Lascaux C, Rouchaud F, Madrangeas V, et al. Planar Ka-band high temperature superconducting filters for space applications. International Microwave Symposium Digest. 2001;01.1 1:487-490.

17. Matthaei GL, Hey-Shipton GL. Concerning the use of high-temperature superconductivity in planar microwave filters. IEEE Transactions on Microwave Theory and Techniques. 1994;42(7):1287-1294. 